\title{
APROXIMACIÓN TEÓRICA A LA DEMOCRATIZACIÓN Y AL FOMENTO DEL ESPÍRITU CRÍTICO EN LAS CIENCIAS DE LA EDUCACIÓN ${ }^{1}$
}

\author{
JOSÉ BARRIENTOS RASTROJO \\ Universidad de Sevilla \\ JUAN R. COCA \\ Universidades de Santiago de Compostela y Valladolid
}

\begin{abstract}
RESUMEN: Este artículo presenta un enfoque teórico sobre el fomento del espíritu crítico. Se defiende la importancia de éste para la democratización. Ello es debido al diálogo presente en nuestra concepción del criticismo pedagógico y a los elementos hermenéuticos. De hecho, nuestra concepción crítica es eminentemente hermenéutica y experiencial.
\end{abstract}

PALABRAS CLAVE: criticismo, democratización, hermenéutica, horizontalidad.

\section{Theoretical aproach to the democratization and the critical spirit promotion in the science of education}

ABSTRACT: This paper presents a theoretical approach about the promoting the critical spirit. We defend its importance for democratization. This one is due to the dialogue present in our conception of pedagogical criticism and the hermeneutic elements. In fact, our view is eminently critical hermeneutics and experiential.

KEY WORDS: criticism, democratization, hermeneutic, horizontality.

\section{INTRODUCCIÓN}

El presente trabajo tiene como objetivo general el estudio de la necesidad de conocer y la indagación sobre la posibilidad de desarrollar mecanismos de innovación docente en la educación superior que permitan incrementar los niveles de empoderamiento de los alumnos universitarios. Esta investigación parte de un proyecto de trabajo transdisciplinar e interuniversitario en el que han participado docentes de historia, de didáctica de la lengua y la literatura, de sociología y de filosofía. Este trabajo constituye el primer texto de nuestro proyecto común en el que se sientan algunas bases teóricas de diversos trabajos posteriores que hemos realizado. Los objetivos específicos son: en primer lugar, sentar las bases de los procesos de democratización educativa y de fomento del espíritu crítico del alumnado de estudios superiores; en segundo lugar, plantear un enfoque educativo que rompe con el paradigma pedagógico tradicional, busca aproximarse a enfoques dialógicos y críticos, al tiempo que asume un carácter herético o profanador del criticismo educativo; por último, pretendemos defender la hermenéutica en el ámbito

1 Este trabajo es parte del Proyecto de Innovación Docente 13-15 «Aplicación de las TEP en el fomento del espíritu crítico y democrático del alumnado universitario» financiado por la UVa. 
pedagógico ya que, sensu stricto y a nuestro juicio ${ }^{2}$, no ha sido muy estudiada en este contexto científico y, más concretamente, en España donde parece que no ha tenido gran interés para los especialistas.

Ahora bien, nuestra intención es la de exponer un enfoque crítico pre-político, más inherente al ser humano que la propia política. En este sentido partimos, como hemos dicho, de una perspectiva hermenéutica que concibe a la persona como ser relacional que establece su sentido en procesos intersubjetivos (Coca, 2010) y, a partir de ahí, será cuando se configure la política como fenómeno de consenso intersubjetivo.

\section{LA PEDAGOGÍA TRADICIONAL: LA AUTORIDAD IDEOLÓGICA COMO PRINCIPIO DE UNA SOCIEDAD} DICTATORIAL

Los principios de la pedagogía tradicional dificultan los mecanismos de participación del estudiante e inducen la relación vertical entre el profesorado y el alumno. La tendencia autoritaria donde el profesor impone contenidos a los alumnos de modo acrítico, quienes lo reciben pasivamente, constituye el eje de esta educación. Esa autoridad no coincide con la auctoritas patrum ideal del senado romano. Aquella no asumía intereses ideológicos en quien la poseía. Además, no se imponía sino que se recibía por el interlocutor; pues, como señala Gadamer «sólo puede calificarse como autorizado a aquel que no necesita apelar a su propia autoridad» (Gadamer, 2001a: 134-135). El docente de la pedagogía tradicional considera que debe ostentar una posición superior a los alumnos debido a sus conocimientos, localización insuperable por aquellos. Su verdad desciende de un poder superior no abierto a la crítica por lo que se quiebran los cauces para la crítica de sus estudiantes.

La proclividad autoritaria incentiva un aprendizaje memorístico antes que uno basado en la comprensión y en el análisis profundo de la materia, puesto que la función es la inserción del niño en el cuerpo de contenidos preestablecidos. Esto entorpece la creatividad y la mudanza del sistema social. En consecuencia, se opera una ausencia de un aprendizaje significativo, una disociación entre lo estudiado y las modificaciones existenciales reales o la incoherencia entre la teoría retenida críticamente y la práctica personal. Más que comprender el mundo se trata de que éste siga los dictados de la teoría. Yendo un poco más allá podría afirmarse también que el autoritarismo educativo se despliega en sistemas políticos dictatoriales, por su oposición al pensamiento crítico, al creativo, a la innovación o a la creatividad que impulsa el cambio (Gómez Mendoza, 2001).

Paulo Freire (1921-1997) ha sido uno de los pedagogos que con mayor profundidad teórica y práctica ha analizado los límites de la pedagogía tradicional, que coincide con su «educación bancaria». Ésta plantea un modelo de roles de profesor y alumno que ha sido resumida en un texto que se ha convertido en un fragmento clásico de su Pedagogia do oprimido:

2 Podemos considerar como ejemplos paradigmáticos de este enfoque los trabajos de Sara Alí Jafella (2002), Raquel Ayala Carabajo (2008), Pamela A. Moss (2005), Herman (2002), entre otros. No englobamos en el mismo entorno los trabajos en pedagogía crítica que asume las hermenéuticas críticas; aunque esto lo hacen de manera tangencial. 
a) o educador é o que educa; os educandos, os que são educados;

b) o educador é o que sabe; os educandos, os que não sabem;

c) o educador é o que pensa; os educandos, os pensados;

d) o educador é o que diz a palavra; os educandos, os que a escutam docilmente;

e) o educador é o que disciplina; os educandos, os disciplinados;

f) o educador é o que opta e prescreve sua opção; os educandos os que seguem a prescrição;

g) o educador é o que atua; os educandos, os que têm a ilusão de que atuam, na atuação do educador;

h) o educador escolhe o conteúdo programático; os educandos, jamais ouvidos nesta escolha, se acomodam a ele;

i) o educador identifica a autoridade do saber com sua autoridade funcional, que opõe antagonicamente à liberdade dos educandos; estes devem adaptarse às determinações daquele;

j) o educador, finalmente, é o sujeito do processo; os educandos, meros objetos (Freire, 1970: 47).

La instilación de estas máximas sobre los educandos gesta consecuencias a diversos niveles, a modo de indicación sucinta apuntamos los siguientes: (1) cognitivamente, la incapacidad de pensar mundos y horizontes alternativos a los establecidos (porque «no saben» ni, fundamentalmente, sabrán crear la utopía que es ensombrecida por los educadores) y a construir sus propios caminos porque «el educador escoge el contenido programático»; (2) volitivamente, la «sumisión» y «docilidad» del educando a la autoridad puesto que son «los pensados»; (3) éticamente, la dimisión del educando de su autonomía y la sujeción heterónoma a los dictámenes del educador (porque el aprendiz se limitan a «seguir la prescripción» una vez ha renunciado al cambio) y la ilusión del pueblo de que mantiene niveles de libertad aceptables a pesar de que esto es sólo una «ilusión autónoma del actuar»; (4) antropológicamente, la pérdida de la posibilidad de ser persona, debido a que los formandos se transforman en objetos o instrumentos para los intereses opresores; (5) sociológica y políticamente, la creación de un imaginario donde los educadores poseen un saber superior e inaccesible para el educando con lo que se constituyen en principio de autoridad y, por ende, la prohibición a construir una sociedad democrática, pues sin sujetos no es posible la participación exigida por esta forma de gobierno (Freire, 2011: 92).

La crítica a las derivas de la pedagogía tradicional forjó a lo largo de la modernidad y la contemporaneidad la creación de sistemas educativos nuevos que pusiesen las bases de alumnos preparados para activar y reactivar la democracia desde pequeños. Sobre eso nos ocuparemos en el apartado siguiente.

3. La CRÍTICA A LA PEDAGOGÍA TRADICIONAL: EL DiÁlOGO EN EL AULA COMO BASE PARA LA CREACIÓN DE LA DEMOCRACIA

\subsection{Los niveles del diálogo en clase: de lo intersubjetivo a lo ontológico}

Martha Nussbaum ha continuado la tradición del pragmatismo de Dewey o de James para destacar la tragedia socio-políticas derivada de una educación asentada 
sobre los pilares de la educación bancaria o de la pedagogía tradicional. Not for profit (2010) es el alegato nussbaumiano contra una sociedad neoliberal que olvida darle el puesto que le corresponden a las artes y humanidades dentro del sistema educativo. Nussbaum no pretende imponer una hegemonía de los estudios humanísticos clausurando asignaturas más técnicas sino luchar contra su erradicación.

Sus razones no resultan de una suerte de corporativismo de su propia área de conocimiento sino de la evidencia de que su desaparición del plano formativo implicaría graves deficiencias para la formación de sujetos democráticos (Nussbaum, 2010: 10). Concretamente, las artes y humanidades: (1) desarrollan el pensamiento crítico y facilitan la superación de las lealtades restrictivas de los localismos a favor de una aproximación global a los problemas como ciudadanos del mundo (Nussbaum, 2010: 7), (2) impulsan la empatía hacia el otro y, por ende, la comprensión profunda de sus perspectivas aun cuando sean contrarias a las nuestras (Nussbaum, 2010: 7), (3) alimentan la investigación y el cuestionamiento de los estudiantes mediante un "active learning» (Nussbaum, 2010: 18) oponiéndose a una "pedagogy of force-feeding for standardized nacional examinations» (Nussbaum, 2010: 19), (4) enardecen el pensamiento creativo (Nussbaum, 2010: 53), imposible allí donde las clases se reducen a largas disquisiciones teóricas no dialécticas ni dialógicas expuestas magistralmente (Nussbaum, 2010: 56).

Queda claro que este modelo se opone a la pedagogía clásica antidialógica y, por el contrario, es congruente con la educación dialógica de Freire (antagonista de la pedagogía bancaria citada arriba). Regresando a Freire, el diálogo es descrito en diversas obras del brasileño, pero la siguiente formulación aglutina de forma clara y concisa sus componentes:

E que é o diálogo? É uma relação horizontal de A com B. Nasce de uma matriz crítica e gera criticidade (Jaspers). Nutre-se de amor, de humanidade, de esperança, de fé, de confiança. Por isso, somente o diálogo comunica. E quando os dois pólos do diálogo se ligam assim, com amor, com esperança, com fé no próximo, se fazem críticos na procura de algo e se produz uma relação de «empatia» entre ambos (Freire, 2011: 95)

Por tanto, el diálogo no sólo es la conversación de carácter crítico entre el maestro y el alumno sino un acto que mezcla un tipo de afecto, humanidad, esperanza y fe en la capacidad del estudiante y confianza entre ambos. De ahí que podemos colegir que el ámbito dialógico en la educación parece estar establecido, según este autor, en un ámbito psicológico, sociológico y axiológico completamente diferente al que durante años ha formado parte de la estructura inherente al sistema educativo. En línea con esto, para nosotros, el ámbito dialógico tiene su fundamento ontológico en la relacionalidad humana. Esta idea no es nueva y ha sido expuesta en autores tan dispares como Martin Buber (1998), quien establece que la palabra básica es yo-tu, Mauricio Beuchot (2004), con su concepción analógica del ser humano, Joaquím Xirau (1983), con su visión amorosa del ser humano, Xavier Zubiri (1998), con su perspectiva relacional de la persona, etc. Estos y otros teóricos del diálogo y la relacionalidad nos han expuesto en diversas ocasiones la intrínseca necesidad de versión, condición erótica, necesidad afectiva, etc. de los unos a los otros. Esta relacionalidad se concatena ontológicamente con el carácter profundamente hermenéutico del ser humano. Pero no sólo eso, Umberto Eco (1992) expuso 
sabiamente que la hermenéutica y la crítica presentan un carácter similar de inquietud. Incluso Eco va más allá y nos muestra que el hermetismo nos indica que un significado no puede ser fijo. Recordemos que el hermetismo tenía pretensiones de transgredir la concepción dominante de la época, el pensamiento griego, y consideraba que podrían establecer nuevas relaciones en el universo. En cierto modo eso mismo lo muestra la hermenéutica. A nuestro juicio, esto también lo expresa el criticismo, pero aquel que no se centra en reivindicaciones políticas, sino en procesos de subversión y transgresión de la cultura.

Volvamos a Paulo Freire. Este autor tiene una configuración muy interesante del diálogo puesto que añade a los dos agentes humanos del diálogo un tercero objetual visto desde una perspectiva particular: el mundo transformándose gracias a la conversación generada dentro del proceso formativo. De aquí, surge una segunda definición del diálogo: «el diálogo es el encuentro amoroso de los hombres que, mediatizados por el mundo, lo «pronuncian», esto es, lo transforman y, transformándolo, lo humanizan, para la humanización de todos» (Freire, 1983: 46). Esta conversación dota de un valor ontológico a la realidad, puesto que lo que existirá será lo que es pronunciado, por tanto, la realidad depende de la lectura que la conversación del aula produzca.

El foco de la conversación educativa pasa de la clásica mirada entre dos sujetos (educador y educando) a la mirada de ambos a un foco previo: la fuente de la que parte el discurso. Aquí volvemos a necesitar converger con la hermenéutica. En este caso en este punto se encuentra Hans Georg Gadamer y su hermenéutica ontológica, quien nos invita a subir un peldaño más para comprender el acto comunicativo dentro del aula: dialogar no sólo abre cauces entre el maestro y el alumno sino que es la única forma de dejar que la realidad se manifieste (por medio de ese diálogo no impositivo). De hecho, el pensador alemán explicita pormenorizadamente el acto comunicativo como sigue:

Llevar una conversación quiere decir ponerse bajo la dirección del tema sobre el que se orientan los interlocutores. Requiere no aplastar al otro con argumentos sino sopesar realmente el peso objetivo de la opinión contraria. En esto [la conversación] es arte de ensayar. Sin embargo, el arte de ensayar es el arte de preguntar; pues ya hemos visto que preguntar quiere decir poner al descubierto y poner en descubierto. Contra la firmeza de las opiniones, el preguntar pone en suspenso el asunto con todas sus posibilidades. El que posee el «arte» de preguntar es el que sabe defenderse de la represión del preguntar por la opinión dominante. El que posee este arte será el primero que busque todo lo que pueda hablar en favor de una opinión (Gadamer, 2001b: 416)

De ahí que una concepción dialógica, hermenéutica y crítica de la educación implica la horizontalidad de las relaciones, el diálogo en equidad (no en igualdad) y el desarrollo cooperativo de las identidades fortalecidas a través de relaciones no verticalizadas y del respeto mutuo. De ahí que gracias a los demás somos o lo que es lo mismo: el otro en calidad de alter me altera (Díaz 2002). Ahora bien eso no quiere decir que dejemos de ser quienes somos.

Pertenecerse unos a otros quiere decir siempre al mismo tiempo oírse unos a otros. Cuando dos se comprenden no quiere decir que el uno "comprenda» al otro, esto es, que lo abarque. E igualmente «escuchar al otro» no significa simplemente realizar a ciegas lo que quiera el otro. Al que es así se le llama sumiso. La apertura 
hacia el otro implica, pues, el reconocimiento de que debo estar dispuesto a dejar valer en mí algo contra mí, aunque no haya ningún otro que lo vaya a hacer valer contra mí (Gadamer, 2001b: 408)

Por todo ello la concepción crítica hermenéutica reflexiona sobre la realidad, sobre las posibilidades futuras, sobre el mejoramiento de la vida de las personas, sobre el cuidado de las mismas en sentido holístico, sobre el respeto intercultural y sobre la pretensión de consecución de un mundo equitativo y horizontal. Una vez establecidos los elementos ontológicos del criticismo que se está proponiendo, ahora sí podemos preocuparnos de otras consecuencias de este criticismo y del diálogo.

\subsection{Diálogo, crítica y profanación}

Regresando a Freire, los dos interlocutores, maestro y alumno en nuestro contexto, se comprometen en un proceso en que no sólo los transforma a ellos mismos sino que establecen las bases para una metamorfosis de lo que les rodea a dos niveles: semántico (leen la realidad de otra forma) y ontológico (crean un nuevo mundo). Desde una perspectiva fenomenológica que equipare ser y aparecer, ambos elementos se unen.

La transformación semántica se materializa en una metodología de trabajo de Freire los círculos de cultura (Gadotti y Torres, 2001: 720). Allí, no se trata de un aprendizaje memorístico de términos sino que con el aprendizaje de los conceptos éstos se sitúan en su mundo, es decir, dialogan con el mundo del que parten en lugar de enseñarlos como entidades abstractas desconectadas del mismo. Por ejemplo, el concepto "pez» será enseñado a los pescadores analfabetos brasileños dentro del contexto las condiciones de explotación que implica los enormes beneficios que una empresa consigue frente a los irrisorios sueldos del trabajador que lo consigue en el mar en medio de condiciones que ponen en riesgo su vida (Freire, 1989: 52-53). Dentro del círculo de cultura, no sólo se aprende que los caracteres «pez» poseen el significado (abstracto y descontextualizado) del diccionario sino su significado en las relaciones de poder del mundo. Ocioso es indicar que la llegada de la dictadura a Brasil en los años sesenta desterró este tipo de educación.

Esta acción transforma el mundo al crear futuros ciudadanos críticos y lucha contra un arquetipo formativo que introduce en el estudiantado información pero establece analfabetos en criticidad. Este analfabetismo era común en la segunda mitad del siglo Xx no sólo entre las capas depauperadas de la sociedad sino entre aquellos que tenían acceso a formación superior en Estados Unidos.

Richard Paul, fundador del Critical Thinking Center y de National Council for Excellence in Critical Thinking en California, se quejaba ya en los años noventa del analfabetismo en pensamiento crítico en los siguientes términos:

Can we conclude then that most Americans are intellectually incapable of rising above childish reasoning, or should we rather hypothesize that as a nation both socially and scholastically we have not yet challenge most people to think for themselves beyond he most primitive levels? Are we, and if so will we remain, what William J. Lederer characterized us in his best selling book of the 1960's, A Nation of Sheep (Paul, 1993: 45). 
La cuestión no era baladí, puesto que deficiencias educativas a este nivel provocarían catástrofes a nivel democrático, en la medida en que «a high level of shared education is essential to a free, democratic society and to the fostering of a common culture, especially in a country that prides itself on pluralism and individual freedom» (Paul, 1993: 45). La crítica es patente en todos los sectores, como muestra podemos apelar a cómo un periodista estadounidense, Michael Kingsley, reitere esta preocupación en sus escritos: avisaba de que gran parte de la ciudadanía no sólo era analfabeta en análisis y conceptualización sino que exigía su «derecho democrático a la ignorancia» (Michael Kingsley citado en Chaffee, 2000: 47). Las características antidialógicas de la pedagogía tradicional y bancaria generan esta ciudadanía que, acostumbrada a un sopor pasivo en las clases bancarias de su infancia y juventud, renuncian (y repudian) su capacidad para razonar críticamente.

Paradójicamente y pese a que en los noventa Paul ya expuso claramente la necesidad de subvertir el paradigma convencional con el objetivo de incrementar el nivel crítico del alumnado, lo cierto es que esto parece que no es objetivo del sistema educativo (desde luego esto es obvio en el caso español). Los autores de este texto sospechan que parece existir cierto recelo a que las personas tomen decisiones de un modo consciente y autónomo. De hecho, la pedagogía tradicional y bancaria (estrechamente vinculada al capitalismo) presenta las características propias del sistema económico en el que se inserta y de donde surge. Por esto las afirmaciones de Walter Benjamin (2011) y de Giorgio Agamben (2005) resuenan constantemente en el análisis del sistema educativo al recordar que el capitalismo se ha conformado en una religión en la que sólo hay culto. Teniendo esto presente es mucho más fácil comprender la necesidad del paradigma tradicional en convertir la práctica educativa en una serie de cultos constantes a los nuevos sacerdotes y sacerdotisas (educadores) que convierten el proceso educativo en una oda y alabanza del libro y del dato, olvidando todas las potencialidades que deben ser potenciadas por los educadores. Así mismo, sigue siendo necesario e incluso urgente que el nuevo sistema educativo tome conciencia de esta realidad educativa y de dicha necesidad democrática. Por esta razón, y pese a que podemos decir que Freire está superado, parece que no caemos en el absurdo al decir que todavía oímos el eco de sus palabras sobre la educación.

\section{RASTROS HistóRICOS DE LA PEDAGOGÍA CRÍTICA}

\subsection{Algunos modelos de la pedagogía crítica en la contemporaneidad}

La pedagogía crítica asume la puesta en cuestión de la globalización, del igualitarismo, así como es consciente de la influencia que el contexto socio-histórico tiene en la conformación del individuo y del sistema educativo. Por esta razón, y dado el devenir actual de la cultura occidental, el criticismo pedagógico ha sentido la necesidad de volver a investigar y analizar la configuración de la identidad colectiva e individual (Kincheloe, 2008: 36). En este sentido Joe L. Kincheloe (Kincheloe, 2004; Kincheloe \& Steinberg, 2013) es uno de los principales estudiosos de este enfoque quien asume elementos de la tradición de la Escuela de Frankfurt, sobre todo referidos a la preocupación por la opresión que el poder ejerce sobre los seres 
humanos, así como la influencia que Freire ejerce a la hora de intentar minimizar el sufrimiento humano. Este autor, siendo consecuente con su planteamiento crítico, afirma que su criticismo - entendido siempre en evolución- sólo muestra interés por aquellas teorías que «aborden de forma directa las necesidades de las víctimas de la opresión y el sufrimiento que deben soportar» (Kincheloe, 2008: 39). Este autor, al igual que otro gran crítico social: Boaventura de Sousa Santos (2002 y 2004; Oliveira, 2006), apuesta por la centralidad de la interpretación, lo que supone aceptar una hermenéutica crítica como parte fundamental del proceso socio-psicoeducativo.

Como acabamos de mostrar Freire está en base de los planteamientos críticos actuales y constituye la punta de iceberg de una tradición de educadores con modelos prácticos donde el diálogo y la horizontalidad son básicos dentro del aula. De hecho, Nussbaum se localiza en una universidad, la de Chicago, donde se iniciaron los procedimientos de la pedagogía crítica de John Dewey. Éste determinaba en Cómo pensamos que el desarrollo del razonamiento enraizaba una educación democrática basándose en varias razones: (1) libera de actividad impulsiva propia de animales (Dewey, 1993: 33). Al pensar racionalmente, el alumno se emancipa de la esclavitud de sus impulsos (Dewey, 1993: 90); (2) aviva la creatividad y la creación de sistemas que escapen de la demagogia conceptual (Dewey, 1993: 34) y (3) enriquece semánticamente a los objetos, que serán más que «cosas» (Dewey, 1993: 35). El pensamiento deweyano no sólo es crítico sino creativo lo cual vacuna contra una pedagogía tradicional que incluyen un "dogmatismo rígido», "rutina» (Dewey, 1993: 50) o hacen "creer que no hay nada por descubrir» (Dewey, 1993: 51). Las deficiencias del marco formativo tradicional le condujo a crear modelos de pensamiento analítico implementables en la escuela que catalizasen «la formación de hábitos de pensamiento vigilantes, cuidadosos y rigurosos» (Dewey, 1993: 82). Ni que decir tiene que incentivar tales hábitos depende del cuestionamiento del profesor y de la bidireccionalidad dentro de la clase. La racionalidad crítica se complementa con la estética: su obra Arte como experiencia (Dewey, 2008) entiende la experiencia estética como la rehabilitación de la vivencia del artista, esto es, la restauración del arte como experiencia gozosa y escapa de esa visión del arte como adormecedora memorización de una historia que hace de la pintura o la escultura medio de ideologización ajena al estudiante.

Matthew Lipman, padre del programa de Filosofía para Niños y alumno de John Dewey, forjará un programa de desarrollo de las capacidades cognitivas, la Philosophy for Children, destinado a alumnado de cinco a dieciocho años. Se comenzó a implementar en Estados Unidos a finales de los años sesenta y, actualmente, se ha extendido por todo el mundo. Su metodología auspicia las habilidades de pensamiento crítico, creativo y cuidadoso con el objetivo de desarrollar una sociedad más democrática. Las clases consisten en la lectura de narraciones donde alumno y protagonista se identifique y en la generación de preguntas que saquen de las ideas establecidas al estudiante. Las contribuciones de Lipman continúan una tradición de pedagogos innovadores que han apoyado la horizontalidad en los intercambios dentro del aula y la participación activa del estudiantado en su formación. La citada Nussbaum rescata algunos de ellos: Rosseau en su Emilio (Nussbaum, 2010: 57-58), Pestalozzi (Nussbaum, 2010: 58-59), Froebel (Nussbaum, 2010: 60-61), Bronson Alcott (Nussbaum, 2010: 61-62), Horace Mann (Nussbaum, 2010: 62-64), 
Tagore (Nussbaum, 2010: 67-73) y los citados Dewey (Nussbaum, 2010: 64-67) y Lipman (Nussbaum, 2010: 73-76). No nos extenderemos en cada uno de ellos por razón de espacio, pero deberíamos destacar algunos aspectos de, al menos, un par de estos autores y otros afines con el fin de introducir en el foco de estas propuestas didácticas.

\subsection{Algunos modelos recientes de la pedagogía crítica}

María Montessori comenzó trabajando con niños en riesgo de exclusión social en las case dei bambini (Roma, 1907). Sus lecciones buscaban desarrollar el pensamiento crítico y estimular la motivación. El profesor funcionaría como facilitador antes que como dispensador de conocimiento. De modo particular, invitaría a la activación en los denominados "periodos sensibles», que consisten en aquellas etapas de la formación en que la sed por saber es mayor. Asimismo, la educación dependería de generar un clima proclive al conocimiento que se denominó montessori enviroment (Montessori, 2009).

A principios del siglo XIX, Friedrich Froebel generó una institución educativa hoy clásica: el Kindergarten o jardín de infancia. Froebel ya muestra un interés por crear una educación no impuesta ni unidireccional, como propondrá también Montessori. La verticalidad del aprendizaje se convertiría en una horizontalidad que no sólo alcanza a la relación entre el profesor y el alumno sino entre estos últimos entre sí. El aspecto lúdico vertebraría una formación que rompería esquemas propios de la pintura de Goya «la letra con sangre entra». Froebel creó juegos como aquel que usa bloques poliédricos que se encajan entre sí y canciones educativas para los estudiantes más tempranos. El proyecto organizó el Instituto para la educación del impulso activo de los niños y los jóvenes. Allí, los colaboradores de nuestro pedagogo inventaron más juegos adaptados a cada edad. A la vista de este itinerario, no resulta extraño que su lema se sintetizase en «juego y trabajo, disciplina y libertad» y que sus clases abominasen de la verticalidad discente y la imposición de contenidos (Froebel, 1989).

En gran confluencia con la filosofía krausista, el modelo educativo de Froebel acampó en España en el seno de la Institución Libre de Enseñanza dirigida por Giner de los Ríos. Se asentaba en los mismos principios de la pedagogía crítica. Acogió a algunos de los principales pensadores y educadores de la primera mitad del siglo xx (como Ortega y Gasset o los hermanos Machado) y, sobre su base, se crearon las primeras instituciones científicas de la actualidad como el Consejo Superior de Investigaciones Científicas, alzado sobre la Junta de Ampliación de Estudios de la Institución Libre de Enseñanza (ILE). La ILE bebía directamente de Froebel y de las pedagogías innovadoras de Pestalozzi por lo que sus emblemas no se separan de las ideas de estos dos teóricos:

Las clases deben ser una conversación, familiar e informal entre maestros y alumnos, llevados por un espíritu de descubrimiento: métodos intuitivos, realidades en vez de abstracciones, objetos en vez de palabras, diálogo socrático, el aula debe ser un taller, el maestro un director, los alumnos una familia (...)

Se propugna el principio de la pedagogía activa y en íntimo contacto con la vida, el método intuitivo, expresión acuñada por Pestalozzi y Froebel. Cuando se funda la Institución Libre de Enseñanza, la influencia teórica central viene de 
estos dos pedagogos y, aunque nunca se abandone del todo, el método intuitivo va modernizándose y enriqueciéndose al contacto cotidiano con las ideas de aquí y de allí hasta alcanzar unas dimensiones plenamente contemporáneas por obra del genio educador de Manuel Bartolomé Cossío (Martínez-Salanova Sánchez, 2014)

Giner de los Ríos quiso romper el elitismo en las clases incentivando la discusión, el aprendizaje vívido dentro y fuera del aula, el modelo de taller dentro de la clase e incluso una familiaridad con el alumnado que permitiera al profesor entrar en su círculo de influencia de un modo más penetrante (Giner, 2004)

Estos pequeños ejemplos nos muestran cuales son las bases de la que parte la rama crítica de las ciencias de la educación. Evidentemente los enfoques actuales son diferentes. En nuestro caso, y como expondremos ahora, están mucho más vinculados al ámbito del lenguaje de lo que estaban los autores antedichos, así mismo nuestra perspectiva es hermenéutica y no tanto psico-pedagógica, al contrario que ellos.

\section{HaCIA UNA PEDAGOGÍA CRÍTICO-RELACIONAL}

La democratización de las sociedades, la promoción de la autonomía, el descubrimiento y desarrollo de la vocación del sujeto, la ruptura con la tiranía acrítica e ideológica, el fomento del pensamiento crítico y creativo, la comprensión profunda del otro y del auténtico diálogo entre los sujetos, la resemantización crítica de la realidad, la quiebra de hegemonía basada en un sistema de privilegios históricos y la promoción de un esquema meritocrático son razones suficientes para incentivar la horizontalidad y la participación dentro del aula inherente a la pedagogía crítica. La cuestión es ahora saber cuáles son las bases antropológicas y ontológicas de una propuesta socio-educativa de tipo crítico-relacional. Como resulta evidente a cualquier planteamiento pedagógico subyace una concepción antropológica y ontológica de la persona. De ahí que los imaginarios sociales que basan el conocimiento de nosotros mismos condicionan los procesos institucionalizados de desarrollo personal $^{3}$. Para ello, lo primero es partir — como la expusimos antes- de una concepción relacional del ser humano.

A este respecto nos centraremos en la propuesta de Xavier Zubiri quien afirma que cada uno está vertido hacia los otros, de tal manera que todos los miembros de la humanidad mantienen una versión mutua (Zubiri, 1998: 193). A través de esa versión nos damos cuenta de las peculiaridades de cada individuo y de cómo necesitamos ser educados en la aceptación de nuestra versión a los demás y de la diversidad humana. Entonces, las demás personas no funcionan como algo con lo que yo hago mi vida, si no como algo que en alguna medida soy yo mismo (Zubiri 2006: 251). Esta nueva concepción del mundo es básica en los procesos educativos para que el alumnado pueda comprender que los otros no nos limitan, sino que

3 Respecto a la influencia de los imaginarios sociales en los procesos de institucionalización y desarrollo de conocimiento no podemos extendernos así que remitimos a BAEZA (2008), CASTORIADIS (1983), Pintos (1995), 
nos abren posibilidades de auto-crecimiento y configuran nuestra propia identidad.

Esta respectividad hace que lo humano presente tres dimensiones funcionales: el «ser-individual, ser-comunal y ser-acrescente» o si se prefiere el «ser individual, comunal e histórico». [E]stos caracteres no son meras propiedades del ser de la realidad sustantiva. [...] No son relaciones extrínsecas, sino caracteres determinados por lo que intrínsecamente es la actividad psico-orgánica en que mi realidad sustantiva consiste»(Zubiri, 1998: 214). Estas tres dimensiones muestran ciertas características comunes. Son graduales, tienen un sentido y una dirección que no están unívocamente determinadas y, por último, están acotadas. A su vez, las tres dimensiones se gradúan y se acotan en función de la convivencia. Ahora bien, estas dimensiones a las que estamos haciendo mención se encuentran habitualmente limitadas por el ejercicio del poder de unos pocos, por el establecimiento de las relaciones verticales subsiguientes y por el establecimiento de unos imaginarios sociales que funcionan negativamente.

Pues bien, en el caso de la primera dimensión, la individualidad, hay que tener presente una serie de cuestiones que tienen gran relevancia en la educación. Esta dimensión es fundamental para que las otras puedan tener lugar. En este sentido Kincheloe (2008) afirma la necesidad de reconstituir al individuo fuera del individualismo abstracto. En cambio, nosotros consideramos que precisamente debemos reivindicar aquello que hace que las personas sean lo que son: personas en relación, pero asumiendo nuestra sustantividad. En base a esto podemos convenir con cierto individualismo mesurado, tal y como hace también Kincheloe, pero éste identifica al individualismo abstracto con una concepción capitalista del mismo y fuera de los condicionantes económicos, sociales y culturales. No estamos de acuerdo. Como científicos tendemos a establecer diferenciaciones que nos permite implementar nuestro conocimiento. Ello no quiere decir que una consideración en abstracto suponga extraer a la persona de sus condicionantes. De hecho, a nuestro juicio, si no hubiese dicha individualidad no podría haber diversidad. Advirtamos lo siguiente:

[La individualidad] «consiste en la manera radical como efectivamente la realidad me constituye en tanto que realidad. No lo real [...] sino mi mismo carácter de realidad es algo que me pertenece en propio: soy mi realidad y no la de otra cosa. Es la realidad personal en cuanto realidad: es individualidad en el sentido de ser «suyo». Es suidad. Y su «ser» es afirmarse como Yo» (Zubiri, 2006: 22).

A su vez, esta diversidad fundamenta la individualidad, ya que es necesario que exista un conjunto de entidades diversas para que cada una de ellas pueda configurarse como individual. Desde esta base se abre la puerta a la dimensión de la comunalidad, la cual está muy relacionada con la convivencia. «De ahí que el ser de la realidad sustantiva de los hombres, de los hombres de hoy, empieza a ser común y comunal en todo el phylum humano» (Zubiri, 1998: 219). Es decir, los procesos de comunicación mundial, de globalización, de transnacionalización, etc. están provocando que la realidad de lo humano sea más planetaria que hace muchos años, pese a que esto traiga consigo problemas de otra índole. En este sentido el filósofo vasco asevera: 
Antes había varias comunalidades; hoy empieza a no haber más que una. Pero esta comunalidad admite grados. No es lo mismo mi ser común respecto de un conciudadano que respecto de un esquimal. El pluralismo acota inexorablemente la comunalidad del ser de cada cual (Zubiri, 1998: 219).

La comunalidad no es una mera colaboración, ni siquiera es un tipo de estatuto, ni una comprensión del otro; es co-realidad constitutiva.

Los hombres son constitutivamente co-reales y constitutivamente no quiere decir que lo sean porque no tienen más remedio, sino que lo que es cada uno es co-real con otros por razón de su propia realidad. La convivencia es un carácter específico de la realidad propia de la sustantividad humana en cuanto tal. No es algo que derive de ello (Zubiri, 2006: 51).

Todo esto que estamos exponiendo gracias a Zubiri nos muestra que nuestra realidad es respectiva hacia los otros. Dicha respectividad está relacionada en el carácter constitutivo de versión que tenemos hacia las demás realidades. «El fenómeno radical de la versión a los otros es precisamente ése: los otros están ya en mi vida configurando la realidad de mi propia vida y por consiguiente, mi forma de autoposesión» (Zubiri, 1998: 238). Por eso, en el proceso vital de cada uno, nos hacemos cargo de la realidad porque dicha realidad (humana) se encuentra ya inserta en nosotros. Esta visión de la relacionalidad humana choca con las reivindicaciones políticas de la pedagogía crítica de Kincheloe o McLaren. Ahora bien es innegable que los procesos de interculturalidad, la educación para la paz y otras perspectivas que se han enfrentado con la concepción moderna de la educación y que presentan concomitancias con la pedagogía crítica es «hija» de la propia modernidad.

\section{CONCLUSión}

La investigación teórica que hemos realizado nos lleva a considerar que el criticismo, pese a tener naturaleza profanadora, tiene que buscar un ámbito de desarrollo prudencial en el que se asuma una visión analógica en la que se acepta cierto relativismo y cierto univocismo a nivel epistemológico, social, económico, ideológico, etc. Recuérdese que, aunque nos pese y sea paradójico, el criticismo tiene también «tintes» ideológicos, al igual que la interculturalidad, la hermenéutica, etc. Todo planteamiento teórico contiene, en cierto modo, ideología en su interior. Por esta razón, como sabiamente exponía la profesora Susana Gómez, toda perspectiva crítica debería, para mantener su espíritu herético, tener vocación de marginalidad. En tal caso, entonces, no se podrá buscar el éxito, el reconocimiento, o la aceptación mayoritaria. Evidentemente parece que ello no sucede así. Ahora bien, ello no quiere decir que el criticismo pedagógico tenga que ser rechazado, sino ajustado a un ámbito menos político, más hermenéutico y personal

Pues bien, para convertir esta propuesta teórica en una realidad se hace necesario realizar, primero, un diagnóstico de la realidad circundante: saber si los ejes de horizontalidad y participación son fomentados desde la palestra y en qué porcentaje es así, descubrir las razones que impiden esta circunstancia y aquellas que fomentarían su despliegue. Sin este análisis previo, las propuestas se quedarían en mera desiderata, en brindis al sol y los abordajes de la pasada pedagogía crítica 
en legado de un pasado utópico que nunca existirá o que lo hará como excepcionalidad en un sistema cuya regla es la contraria.

El presente trabajo que comienza con este artículo pretende tomar el pulso al sistema educativo actual con el fin de establecer bases de intervención social en esta área de la realidad desde una concepción hermenéutica y relacional del ser humano.

\section{Bibliografía}

Agamben, G. (2005), Profanaciones. Buenos Aires: Adriana Hidalgo editora.

Ayala Carabajo, R. (2008), «La metodología fenomenológico-hermenéutica de M. Van Manen en el campo de la investigación educativa. Posibilidades y primeras experiencias», Revista de Investigación Educativa, 26 (2): 409-430.

BaEzA, M. A. (2008), Mundo real, mundo imaginario social. Santiago de Chile: R.I.L.

Benjamin, W. (2011), "Capitalismo como religião», Revista Garrafa, 23. Accesible em: http:// www.ciencialit.letras.ufrj.br/garrafa/garrafa23/jandedemelo_capitalismocomo.pdf. Acceso: 28 de diciembre de 2014.

Beuchot, M. (2004), Hermenéutica, analogía y símbolo. Barcelona: Herder.

Buber, M. (1998), Yo y Tú. Madrid: Caparrós.

CAstoriadis, C. (1983), La institución imaginaria de la sociedad. Barcelona: Tusquets.

ChAFFEe, J. (2000), El poder del pensamiento. Barcelona: Planeta.

Coca, J. R. (2010), La comprensión de la tecnociencia. Huelva: Hergué.

Dewey, J. (1993), Como pensamos. Nueva exposición de la relación entre pensamiento reflexivo y proceso educativo. Barcelona: Paidós.

- (2008), Arte como experiencia. Barcelona: Paidós.

Díaz, C. (2002), ¿Qué es el personalismo comunitario?, Emmanuel Mounier- SOLITEC- IMDOSOC- Universidad de Culiacán- Yoltéotol, Salamanca.

Eco, U. (1992), Los límites de la interpretación. México: Lumen.

Freire, P. (1970), Pedagogia do oprimido. Rio de Janeiro: Paz e terra.

- (1983), Extensão ou comunicação. Rio de Janeiro: Paz e terra.

- (1989), A importância do ato de ler. São Paulo: Cortez editores.

- (2011), Educação e mudança. Rio de Janeiro: Paz e Terra.

Froebel, H. (1989): L'educació de l'home i el jardín d'infants. Barcelona: Eumo.

Gadamer, H. G. (2001), El estado oculto de la salud. Barcelona: Gedisa.

- (2001b), Verdad y método I. Salamanca: Sígueme.

Gadotti, M.; Torres, C. A. (2001), Paulo Freire: una biobibliografía. México DF: Siglo xxi.

Giner de los Ríos, F. (2004), Obras selectas. Madrid: Austral.

Gómez Mendoza, M. (2001), «El modelo tradicional de la pedagogía tradicional: orígenes y precursores", Revista de ciencias humanas, $\mathrm{n}^{\circ} 28$, Risaralda (Colombia). Accesible en: http://www.utp.edu.co/ chumanas/revistas/revistas/rev28/gomez.htm. Acceso 20 de diciembre de 2014.

Herman, N. (2002), Hermenéutica e Educação. Río de Janeiro: DP\&A.

JAFELLA, S. A. (2002), «Aperturas hacia un retorno al pensamiento filosófico y pedagógico de Dilthey», Revista de Filosofía y Teoría Política 34. Disponible online en: http://www.fuen tesmemoria.fahce.unlp.edu.ar/art_revistas/pr.149.pdf. Acceso: 28 de diciembre de 2014.

Kincheloe, J. L. (2004), «The Knowledges of Teacher Education: Developing a Critical Complex Epistemology», Teacher Education Quarterly, Vol. 31, n 1: 49-66.

Kincheloe, J. L. (2008), «La pedagogía crítica en el siglo xxi: Evolucionar para sobrevivir». En: Mclaren, Peter y Kincheloe, J. L. (Eds.) Pedagogía crítica. De qué hablamos, donde estamos. Barcelona: Graó, 25-68. 
Kincheloe, J. L., \& Steinberg, S. R. (1993), «A tentative description of postformal thinking: The critical confrontation with cognitive theory. Harvard Educational Review, 63(3): 296320. Retrieved from http://her.hepg.org/content/h423221 226v1 8648/

Martínez-Salanova Sánchez, E., «Francisco Giner de los Ríos y los pedagogos de la Institución Libre de Enseñanza», disponible online en www.uhu.es/cine.educacion/figuraspedago gia/0_ginerdelosrios.htm, último acceso 15 de diciembre de 2014.

Montessori, M. (2009), El método de la pedagogía científica: aplicado a la educación de la infancia en las "cases dei bambini». Madrid: Biblioteca Nueva.

Moss, P. A. (2005), «Understanding the other/Understanding ourselves: Toward a constructive dialogue about «Principles» in educational research», Educational Theory, 55 (3): 263283.

Nussbaum, M. (2010), Not for profit. Why democracy needs the humanities. Princeton: Princeton University Press.

Oliveira, I. B. (2006), Boaventura \& a educação. Belo Horizonte: Autêntica.

PAUL, R. (1993), Critical Thinking. What every person needs to survive in a rapidly changing world. California: Foundation for Critical Thinking.

Pintos, J. L. (1995), Los imaginarios sociales. La nueva construcción de la realidad social. Bilbao: Instituto Fe y Secularidad/Sal Terrae.

SÁNCHez CAPDEQuí, C. (1999), Imaginación y sociedad: una hermenéutica creativa de la cultura, Madrid, Tecnos.

Santos, B. de S. (2004), Um discurso sobre as ciências. São Paulo: Cortez.

SAntos, B. de S. (2002), A crítica da razão indolente: contra o desperdício da experiência. São Paulo: Cortez.

Schmidt Andrade, C. (2013), «Proyectos educativos desde la hermenéutica analógica», Educação e Filosofia, 27 (53): 297-322.

XIRAU, J. (1983), Amor y mundo. Barcelona: Península.

ZuBIRI, X. (1998), Sobre el hombre. Madrid, Alianza.

ZuBIRI, X. (2006), Tres dimensiones del ser humano: individual, social, histórica. Madrid: Alianza.

Universidades de Sevilla,

José BARRIEnTos RASTROJO

Santiago de Compostela. y Valladolid

juancoca@soc.uva.es

JUAN R. Coca

[Artículo aprobado para publicación en diciembre de 2015] 